\title{
THE THEATRE OF AITOLIAN MAKYNEIA ${ }^{2}$
}

\section{INTRODUCTION}

ExCAVATIONS by the 6th Ephorate of Prehistoric and Classical Antiquities, directed by L. Kolonas, ${ }^{2}$ brought to light between 1984 and 1989 remains of a small, well-preserved ancient theatre in the archaeological site at Paliokastro Mamakou, close to the modern village of Makyneia, near Antirrion. The theatre, looking east and south, is adapted to the local topography, partly carved into the slope of the fortified acropolis hill and partly lying on a gently inclined plateau, about $12 \mathrm{~m}$ from the remains of a temple (FIGS. 1-3).

Very little is known about this theatre: the available information is contained in a short excavation report, in which the unusual pattern of this theatre, dated to the third century $\mathrm{BC}$ and consisting of a koilon and a linear proedria wing, was recognized, ${ }^{3}$ as well as in a passing reference and a photograph published in a tourist book dating this theatre to the late fourth century $\mathrm{BC} .4$

In 1998 a topographical study of the fortifications, the temple, and the theatre was carried out amongst the research activities of the Geodesy and Geodetic Applications Laboratory of the Department of Civil Engineering of Patras University.

In this article we summarize the results of the 1998 study of the ancient theatre, of subsequent measurements, as well as of a geometrical analysis of the ancient structure.

\section{Geography, Topography, and History of the Ancient Town}

The ancient town at Paliokastro hill, which dominates the large and fertile plain of modern Makyneia, somewhat isolated by sea and high mountains, occupies a nearly flat-topped hill, approximately $130 \times 70 \mathrm{~m}$ wide and $187 \mathrm{~m}$ high. This hill, overlooking the RionAntirrion Straits and the wider region, is crowned by ruins of walls of pseudo-isodomic masonry about $400 \mathrm{~m}$ long. ${ }^{5}$ Foundations of a few public buildings and of houses have been identified inside the walls, while remains of public and private houses, including a temple and the theatre, as well as a cemetery, have been found outside the walls, on the lower slopes of the hill (FIG. 1). ${ }^{6}$

\footnotetext{
' We are indebted to L. Kolonas, former Head of the 6th Ephorate of Antiquities at Patras and excavator of Makyneia for encouragement, granting permission for the topographic study of the Makyneia antiquities, and providing unpublished data. Elizabeth Gebhard is deeply thanked for constructive suggestions, help with literature, and corrections of various versions of this manuscript. Her contribution in the understanding of the architecture of early theatres and the drafting of this article was crucial. Aris Chasapis is thanked for his help in the fieldwork. Comments by an anonymous reviewer are also appreciated.

Abbreviations:

Dinsmoor $=$ W. B. Dinsmoor, The Architecture of Ancient Greece, $3^{\text {rd }}$ edn. (London, 1950).

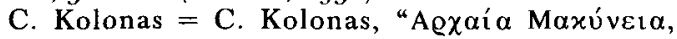

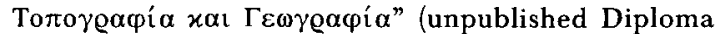
thesis, Department of Civil Engineering, Patras University, 1998).

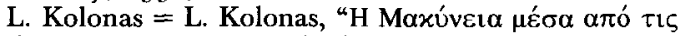

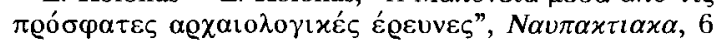
$(1992 / 3), 79^{-} 95$.

2 L. Kolonas.

3 C. Kolonas.

4 S. Bommeljé and P. Doorn, A Provisional Gazetteer of Aetolian Sites (Studia Aetolica, 1; Utrecht, 1987), 95; Greek Tourist Organization (EOT), Greece: Cultural Heritage, Ancient Theatres (Athens, 1996).

5 W. Woodhouse, Aetolia: Its Geography, Topography and Antiquities (London, 1897), 327.

${ }^{6}$ L. Kolonas. 


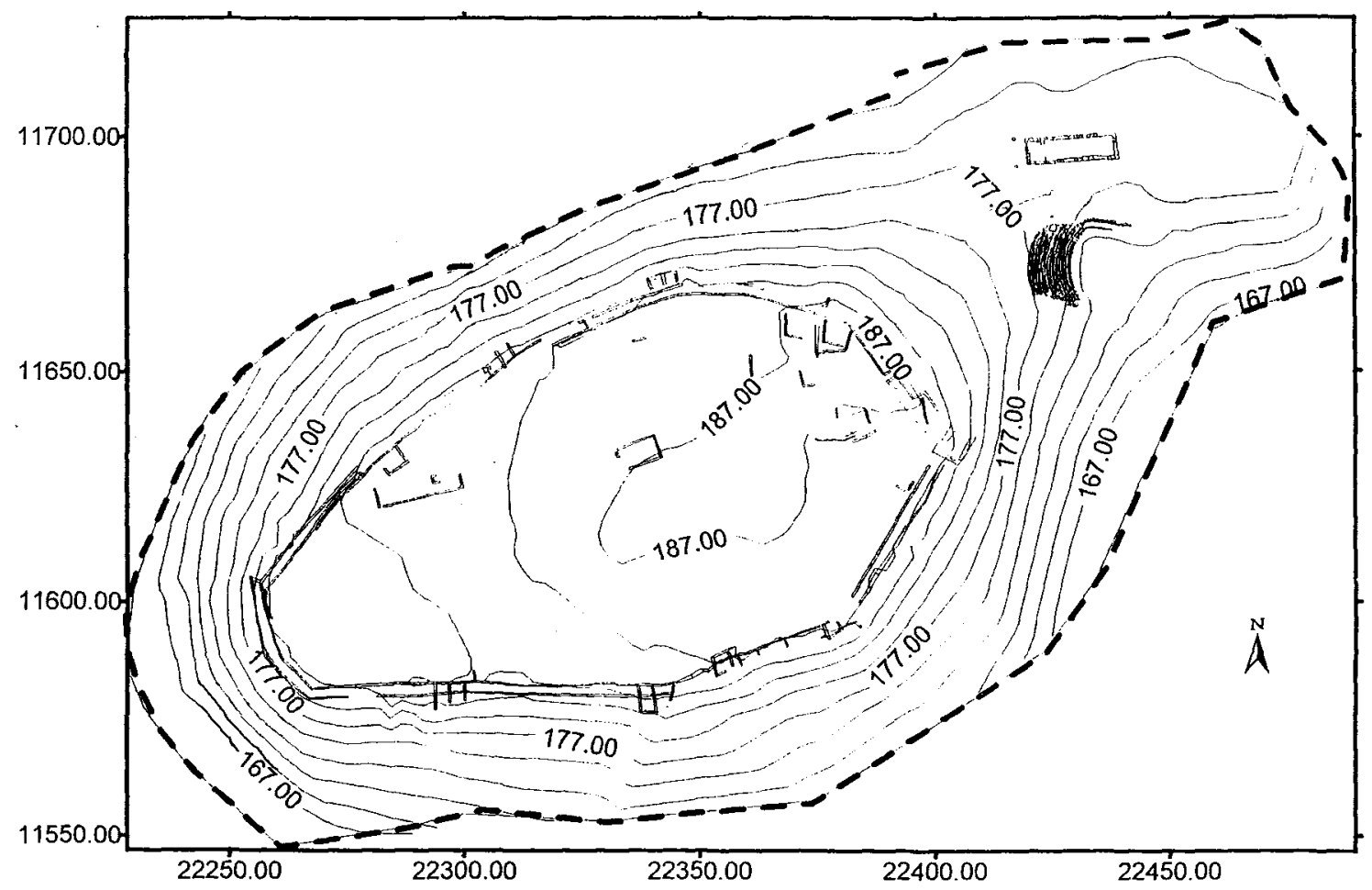

FIG. 1. Topographic plan of the archaeological site at Makyneia, showing fortifications, the theatre and the temple (after C. Kolonas).

Because of its geography and strong walls, the ancient town at Paliokastro Mamakou has been identified with ancient Makyneia, a fortified Aitolian town known from literary sources. ${ }^{7}$ However, for lack of epigraphic or other precise evidence, this identification remains a matter of debate. ${ }^{8}$

According to historical sources, Makyneia was among the important fortified Aitolian towns which were destroyed $c .197 \mathrm{BC}$ by Philip V, King of Macedonia. It is therefore likely that Makyneia shared the same fate as other Aitolian towns which flourished in Hellenistic times, but thereafter declined or were abandoned. This result is confirmed by the distribution diagrams of the number of ancient sites in Achaia and Aitolia showing a characteristic peak during the Hellenistic period (FIGS. 4-5).

Evidence for precise dating of the site based on stylistic evidence is not conclusive. Sherds collected during the surface surveys from the fortifications and the surrounding area belong to the third century $\mathrm{BC}$ according to the excavator's report, ${ }^{9}$ while other investigators have dated the fortifications to the fourth or third century $\mathrm{BC}$, and surmised that the whole site remained in use throughout Hellenistic and possibly into Roman times. ${ }^{10}$

7 Woodhouse (n. 5).

${ }^{8} R E$ Aitolia, cols. 816-17; Bommeljé and Doorn (n. 4); L. Kolonas.
9 L. Kolonas.

${ }^{10}$ RE Suppl. VI, Makynia; Boomeljé and Doorn. 


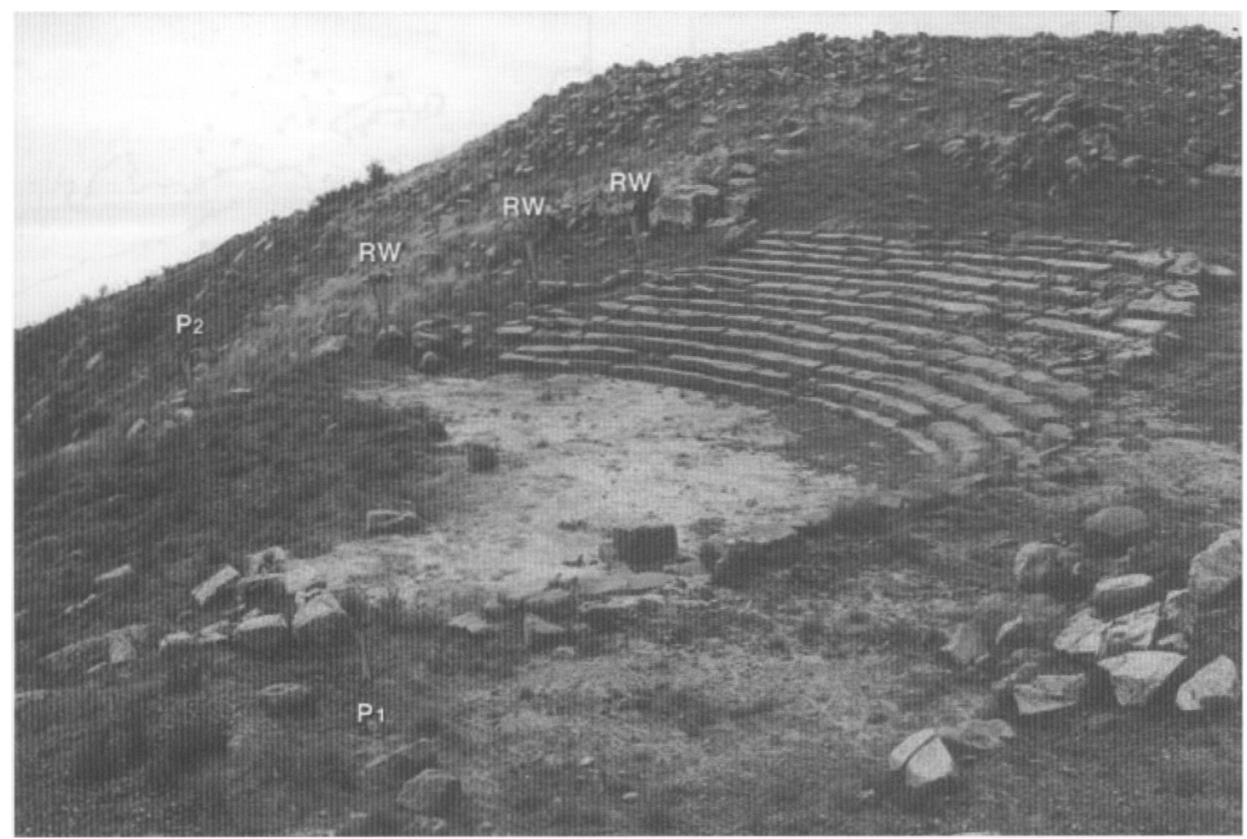

FIG. 2. The theatre, view from the east. The rectilinear proedria wing is shown. In the background, remains of the fortifications are faintly visible on the top of the hill.

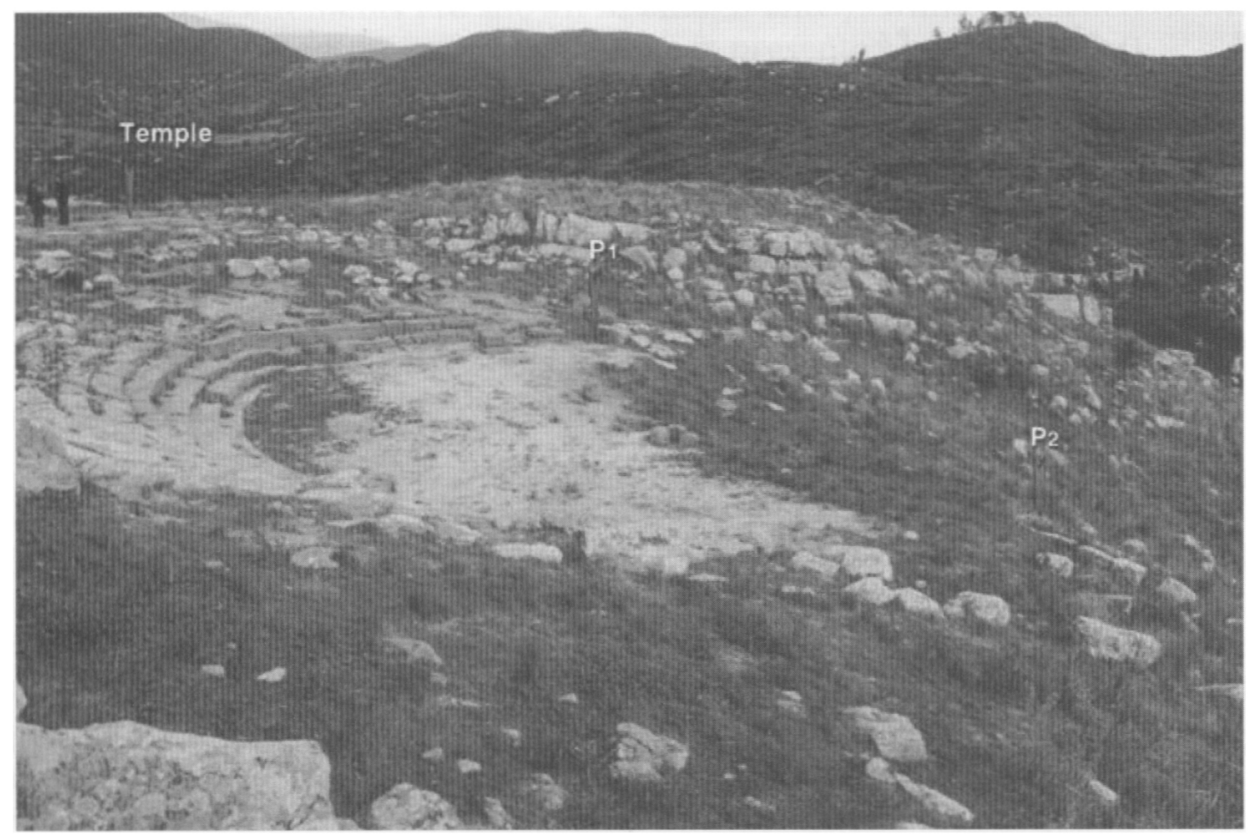

FIG. 3. The theatre, view from south. Behind the rectilinear proedria wing is a gently sloping plateau with no ancient remains, and at a distance of $12 \mathrm{~m}$ the foundations of a temple. 

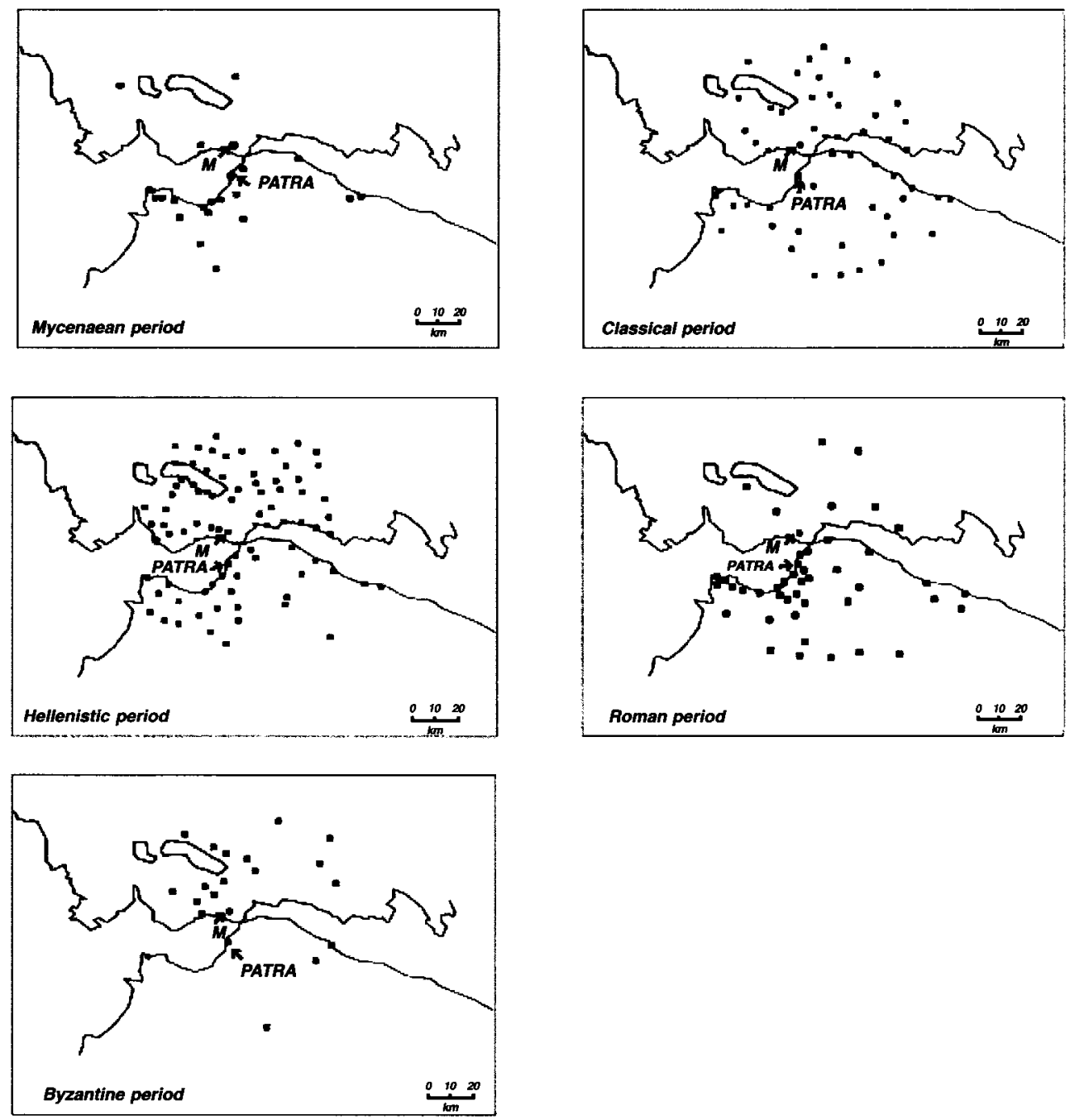

FIG. $4(a-e)$. Ancient sites in Aitolia and Achaia in antiquity, after C. Kolonas. Based on unpublished data of the 6th Ephorate of Prehistoric and Classical Antiquities.

\section{Topographical Survey of The Theatre}

A topographical survey of the ancient site, including the theatre, was made in 1998. The plan of the theatre was compiled based on automatic surveying techniques (i.e. using a total station electronic theodolite). A small plastic reflector (instead of a normal prism) was placed at the four corners of each hewn block, and measurements were automatically recorded by the theodolite. Data were reduced using the VERM software and were electronically plotted. This process permitted an easy, rapid, and accurate survey of the 

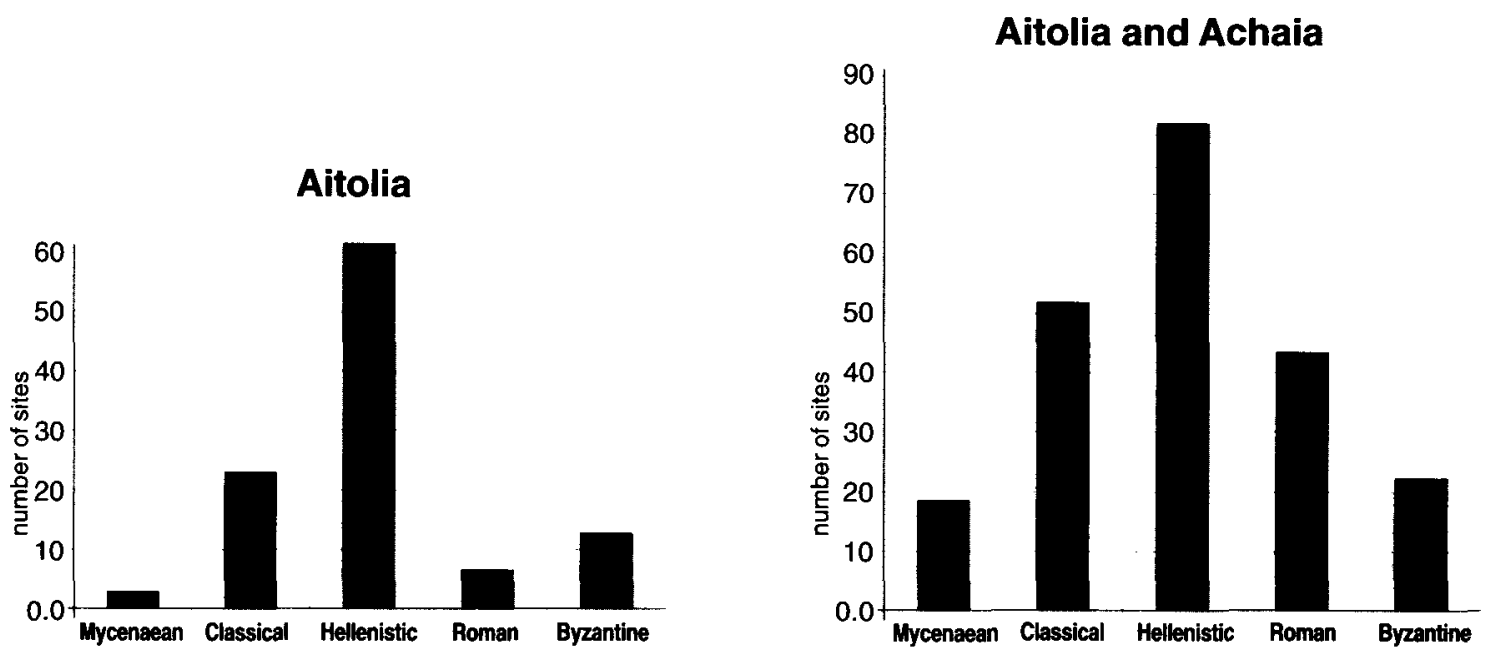

FIG. 5. Diagrams showing the frequency of distribution of ancient sites identified $(a)$ in Aitolia and $(b)$ in Achaia and Aitolia. Based on data of C. Kolonas.

ancient remains at the resolution necessary to understand the plan of the ancient structure. ${ }^{11}$ The plan and a section of the ancient structure derived from the 1998 topographic survey and subsequent measurements are shown in FIGS. 6 and 7 , while a detailed description of the ancient remains based on our observations is presented below.

From the plan and the cross section of the theatre it was calculated that the average value of the spacing of seats, calculated on the basis of the lower eleven, best preserved rows of blocks is approximately $0.66 \mathrm{~m}$, while the average height of seats and the angle of inclination of the curvilinear part of the cavea are $0.28 \mathrm{~m}$ and $21^{\circ}$ respectively. A more precise estimate of the spacing of rows of seats is presented below.

\section{Structure of the Ancient Theatre}

\section{CURVILINEAR (MAIN) WING}

The rock of the hillside has been cut back to create a part of the cavea. Local flysch, however, which consists of chaotic alternations of thick and thin slabs of high-strength sandstone and of unconsolidated deposits and represents the building material for the whole of the surviving structure, does not permit rows of seats to be excavated, as is the case with other older theatres usually cut in limestone. ${ }^{12}$ For this reason, where necessary, a hollow was formed in the cliff and the seats were subsequently built of large sandstone

1 C. Kolonas.

12 Argos: R. Ginouvès, Le Théâtron à gradins droits et l'Odéon d'Argos (École Française d'Athènes, Études péloponnésiennes, 6; Paris, 1972), 61-2, 74, 76; Syracuse: G. V. Gentili, 'Nuovo esempio di 'theatron' con gradinata rettilinea a Siracusa', Dioniso, 15 (1952), 12242; Chaeroneia: C. Anti and L. Polacco, Nuove ricerche sui teatri greci arcaici (Padua, 1969), 19-44; Isthmia: E. Gebhard, The Theater at Isthmia (Chicago and London, 1973), 16, 137. 


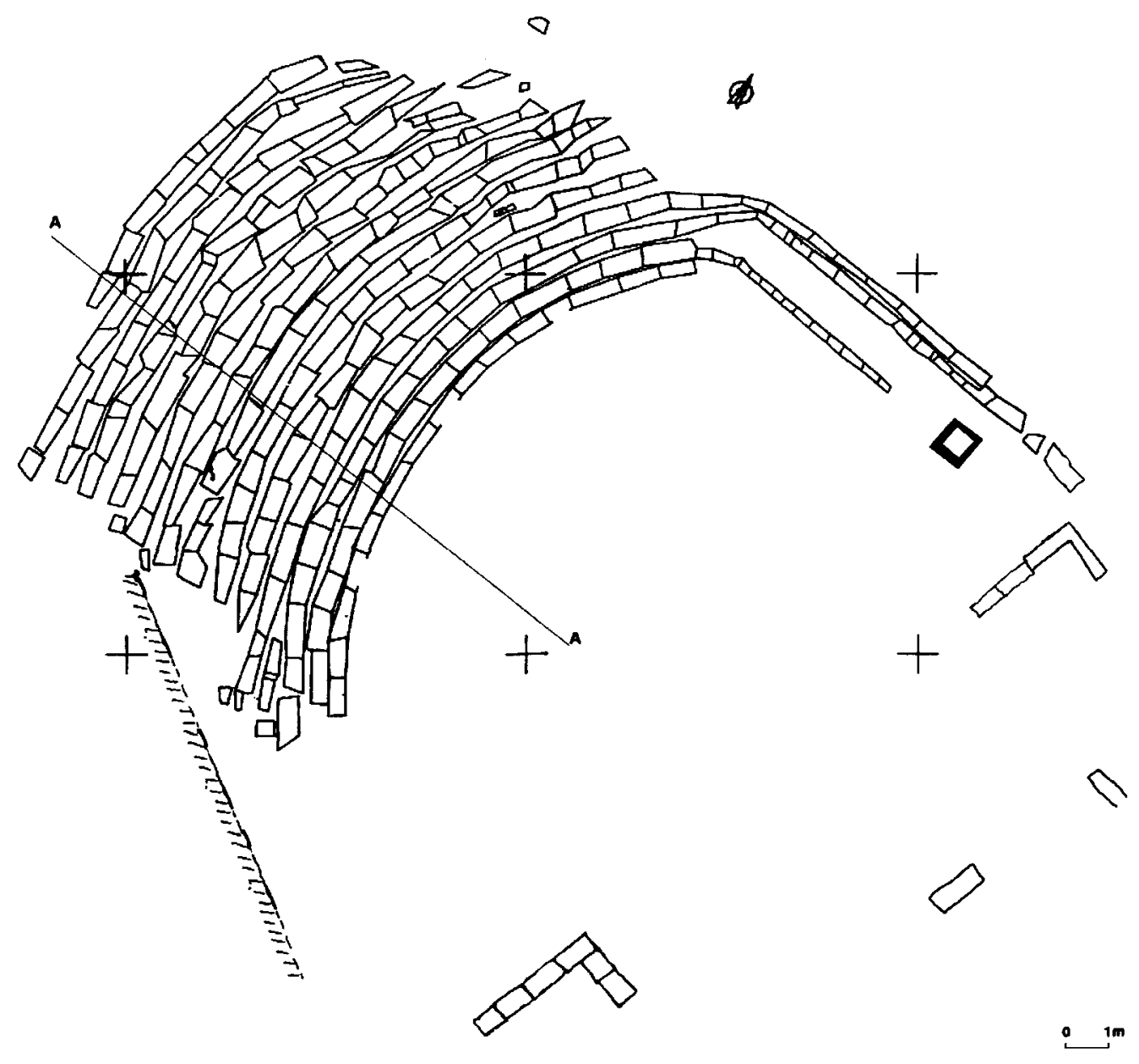

Fig. 6. Plan of the Makyneia theatre. Modified after C. Kolonas. The remains of backrests behind the third (upper) course of blocks of the linear wing are not shown.

slabs (usually about $1 \mathrm{~m}$ long). The blocks of the lowest (first) row are slightly longer (average length $1.2 \mathrm{~m}$ ) but less deep than those of the upper rows, and of better craftsmanship. Most of these slabs are in situ, although slightly tilted or displaced because of their unstable foundation. Fourteen rows of seats are preserved. Some of the lower rows appear to be longer (FIG. 6), but this is probably due to accumulation of displaced blocks to the south or their continuation to the rectilinear wing to the north. The three upper rows are less well preserved; especially the highest one, in which few blocks are preserved in situ. No signs of stairways are visible. The terminal blocks on both sides of each row of seats give the impression that, with the exception of certain displaced blocks, the surviving part of the central wing can be roughly inscribed in a rectangle bounded by two sub-parallel straight lines (FIGS. 3,6 ). 


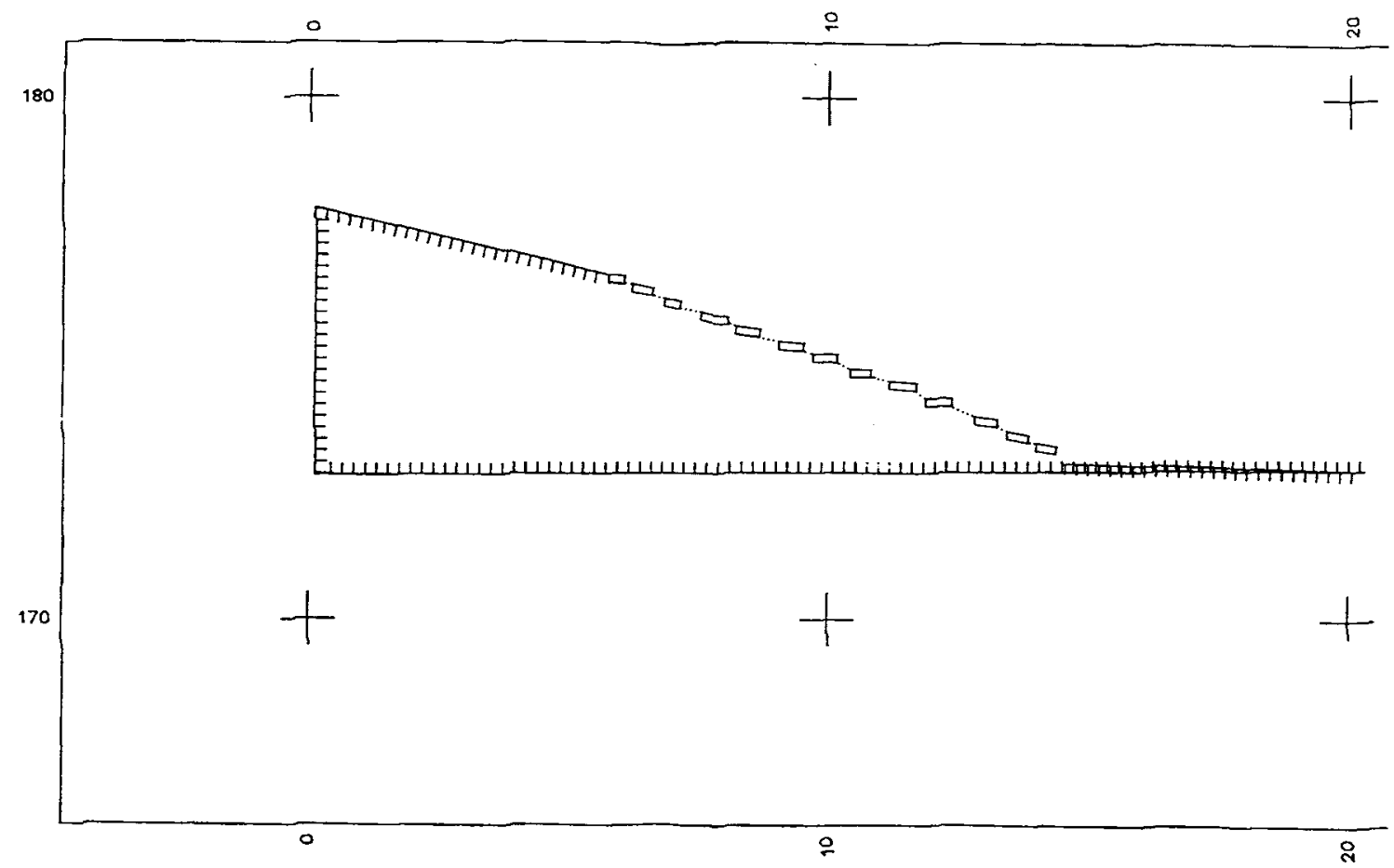

FIG. 7. Vertical cross section of the Makyneia theatre along the axis marked in FIG. 6. (after C. Kolonas).

\section{RECTILINEAR WING}

The rectilinear wing is approximately parallel to the axis of the curvilinear wing. It consists of three unevenly spaced rows of blocks which form three steps and represent the extension of rows 2,3 , and 4 of the central wing, to which they are connected through curved segments (FIGS. 3, 6, 8). Behind this wing no ancient remains were observed on the smoothly inclined area extending up to the flat area of the temple (FIGS. 1, 3).

The lowermost row in this wing, made of smaller blocks (about $20 \mathrm{~cm}$ long), is at the continuation of the second row of the curvilinear wing and rests on top of the terminal block of its first (bottom) row of seats. Since at the time of our observations sediment had accumulated at the northern part of the orchestra, up to the level of the lowermost row of blocks, partly burying the north terminal block of the circular wing, no further detailed observation could be made (FIGS. 3,8 ).

In their central part the three rows of blocks of the rectilinear wing are parallel and form three steps covering a zone approximately $2 \mathrm{~m}$ wide. The upper step is approximately $5^{\circ} \mathrm{cm}$ wide, and behind it there is evidence of vertical slabs $8-10 \mathrm{~cm}$ thick and $25-30 \mathrm{~cm}$ high, probably backrests, mostly not in situ during our field surveys. The width of the middle step, which can be followed for about $8.5 \mathrm{~m}$, is $35 \mathrm{~cm}$ on average, too narrow to represent a row of seats; most likely it represents a footrest for the seats of the upper row. The lower (first) row of smaller blocks is at a distance of $1 \mathrm{~m}$ from the middle row and may represent either a platform to elevate the proedria, or perhaps another row of seats, 


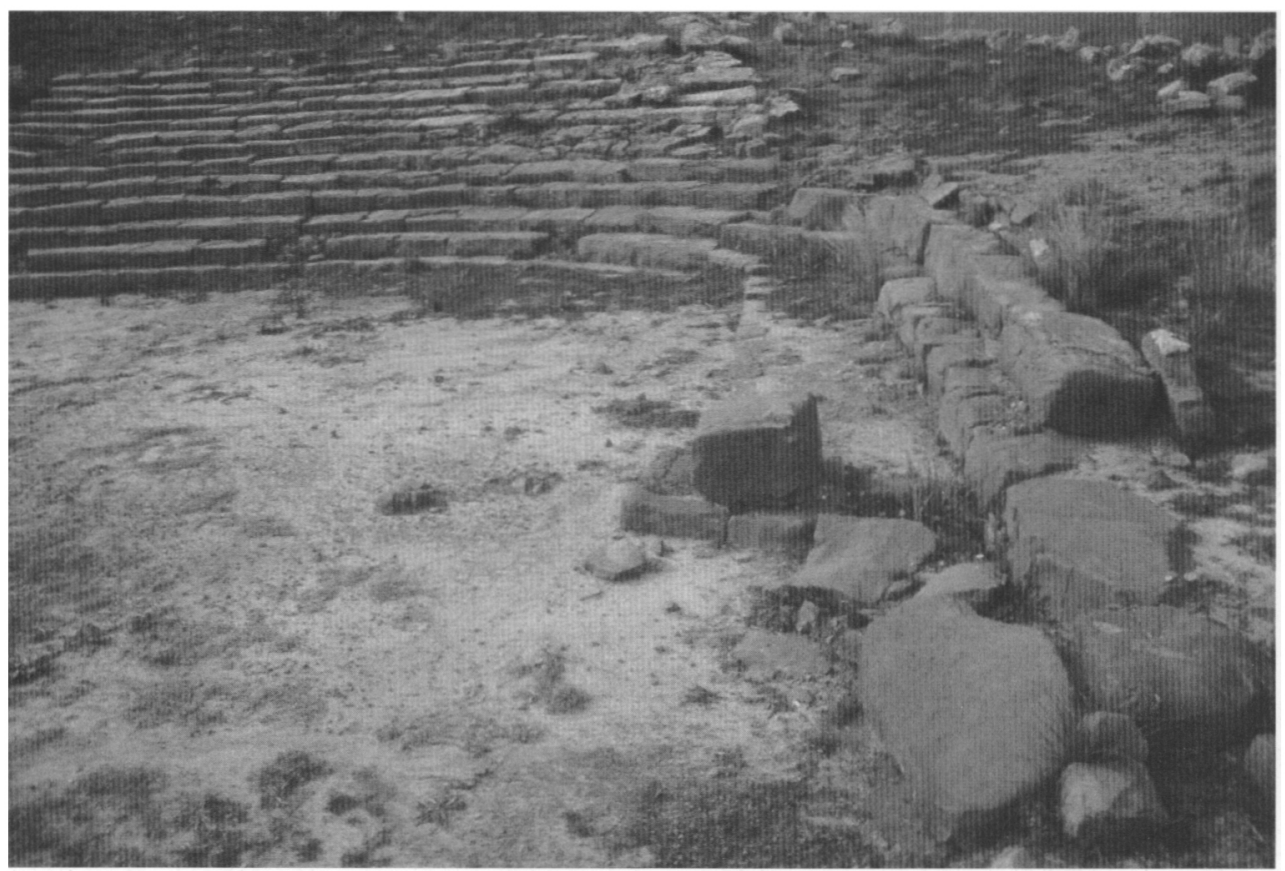

Fig. 8. The rectilinear wing (proedria), view from the east.

perhaps with wooden backrests. This row of blocks is shorter than the second: a nearly rectangular block lying on a rectangular base, a 'throne' according to the excavator, is found at its extension, at a slight angle to the line of seats. This structure is in situ, at least as far as its base is concerned, which is rectangular, $87 \mathrm{~cm}$ wide and $10_{5} \mathrm{~cm}$ deep, made of smaller hewn rocks. On top of this base is a nearly rectangular block, $68 \mathrm{~cm}$ wide, $5^{6} \mathrm{~cm}$ deep, and $43 \mathrm{~cm}$ high at its front part, which is at a distance of $35 \mathrm{~cm}$ from the front of the base. The NW corner of this block is roughly aligned with the front of the first row of seats of the linear wing. The upper surface of this block is gently inclined towards the orchestra, but no signs of rock-cuttings which could support a wooden cover and back support, necessary for sitting comfortably, are visible (FIG. 8). This enigmatic structure seems therefore to be in a position very similar to another enigmatic structure located in a void (or better a recess of the wing) at the SE edge of the east wing of the Thorikos theatre; this last structure has been interpreted as an altar contemporary with the stone seats. ${ }^{3}$

\section{SKENE}

Poor remains of foundations in the area of the skene were visible at the time of our study, but as this part of the theatre is on the cliff, most remains have been obliterated or are displaced and do not permit a clear plan of this structure. The most important of these 
remains is a line of two sets of hewn blocks extending $20.15 \mathrm{~m}$, forming an angle of $81^{\circ}$ to the direction of the linear wing. Few of these blocks are definitely in situ. These blocks may correspond to the foundations of the north corners of the skene building (points $P_{1}$ and $\mathrm{P}_{2}$ in FIGS. 2, 3, 9). Point $\mathrm{P}_{1}$, in particular, which is about $0.70 \mathrm{~m}$ north of the line of the front row of the linear wing, is at a distance of about $1 \mathrm{~m}$ from the surviving terminal block of this wing and may define a parodos. At $3.40 \mathrm{~m}$ east of the front of the possible skene, remains of a second line of foundations are preserved extending $8.80 \mathrm{~m}$ (FIG. 6).

\section{OTHER REMAINS}

Remains of an oblique wall at the south side of the cavea (FIG. 6 and RW in FIG. 2), giving the impression of a corridor $55 \mathrm{~cm}$ wide at its narrowest point, was also observed. This wall, if contemporary with the cavea, excludes the possibility of rows of seats originally extending farther to the south.

\section{Capacity of The Theatre}

The capacity of the theatre of Makyneia can be estimated from the cumulative length of the rows of seats and the average spacing of theatres, ranging between 0.33 and $0.41 \mathrm{~m}^{1{ }^{14}}$ Assuming that the curvilinear wing was not very different from the surviving structure, the total length of fourteen rows is $c .24^{-}-25^{\circ} \mathrm{m}$, corresponding to a seating capacity of c.70o people. At least ten people sat on the linear wing, while it is likely that less privileged citizens stood or sat in wooden scaffoldings ( $i k r i a)$ behind the linear wing. ${ }^{15}$ This relatively high seating capacity for the dimensions of this structure is, however, obtained at the expense of comfort: the average height of the seats is $0.28 \mathrm{~m}$, while in most other theatres it is $0.31-0.40 \mathrm{~m} .^{16}$

\section{GeOMETRY OF THE ThEatre}

The main questions arising are whether the curvilinear wing of the cavea corresponds to an arc of a circle, and whether there exists a geometric relationship between the linear and the curvilinear wings. The plan of the theatre does not permit an easy answer to this question, for many of the seats appear to be displaced from their original position. For this reason we tried to answer these questions based on both graphic and analytical approximation techniques. Our study, however, was confined to the remains of the cavea, and ignored those in the skene, both because of their poor degree of preservation and their unusual, oblique direction.

\section{GRAPHIC APPROACH}

At a first step we adopted the approximate, graphic method proposed by C. Palyvou in her study of the Thorikos theatre: ${ }^{17}$ with the aid of transparent paper, on which equidistant

14 Dinsmoor 247; Gebhard (n. 12), 70.

15 Dinsmoor 120 n. 1,209 n. 4, 249.

${ }^{6} \mathrm{C}$. Palyvou, 'Notes on the geometry of the ancient theatre of Thorikos', $A A 2001 / 1,45-58$ at $56 ; \mathrm{R}$. Frederiksen, 'Typology of the Greek theatre building in late classical and Hellenistic times', Proceedings of the
Danish Institute at Athens, 3 (2000), 135-75, Fig. 8.

${ }_{17}$ Palyvou (n. 16), 51-2; E. Gebhard, 'Vitruvius and the planning of the Greek theater', in A. Alexandri and

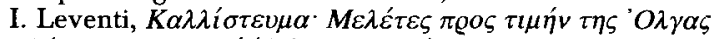

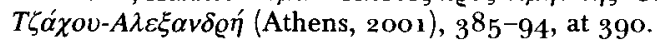


concentric cycles were drawn, we tried to identify the circles that best fitted the lines of the seats of the curvilinear wing. In this analysis we focused on structural elements apparently in situ, avoiding whole rows (for instance the uppermost two), parts of the rows or individual blocks which appeared slightly displaced.

The results of this approach which are shown in FIG. 9 revealed that, within the uncertainties of the data and the graphic technique, the curvilinear part of the theatre seems to have been constructed on the basis of concentric circles. The centre of these circles (C in FIG. 9 ) is located inside the orchestra, about $1.5 \mathrm{~m}$ in front of the remains in the area of the Skene.

A question arising was the determination of the arc corresponding to the lower row of seats. We assumed that the surviving southern and northern terminal blocks were the original terminal blocks. The precise length of the latter could not be measured during our field surveys because it was buried by sediment (see FIG. 8), but it was estimated on the basis of the assumption that it was equal to the average length of all surviving blocks of this row, $1.2 \mathrm{~m}$. We could then define the chord $\mathrm{AB}$ of the arc of the lower row of seats, between the edges of the southern and northern terminal blocks and estimate the corresponding angle as $c .90^{\circ}$.

The three linear rows of blocks define parallel lines which are approximately perpendicular to $\mathrm{AB}$. This is likely to indicate that the linear wing was designed parallel to the inferred axis of symmetry of the circular part of the cavea ('design axis' CD in FIG. 9). This indicates that the orchestra was at least at its northern part designed on the basis of a square. Yet the remains of the skene are oblique to the directions of this square (FIG. 9).

\section{ANALYTICAL APPROACH}

In order to improve the modelling, we approximated the curvilinear rows of seats by equidistant concentric circles and those of the rectilinear wing by parallel straight lines using an analytical technique. The two wings were analysed separately.

For the curvilinear wing, input in our analysis were the mean coordinates of the front edges of each block apparently in situ, using an arbitrary coordinate system. For each block a second-order equation was defined expressing the distance between the (unknown) circle centre and the mid-point of its front face. The system of these equations was solved for five unknown parameters (the two coordinates of the circle centre, the radius of the first row, the spacing between the two lower rows and the spacing of all upper rows; FIG. 10) and their standard errors were computed with the least squares method. The geometric pattern of the theatre was subsequently defined on the basis of the adjusted data.

This analysis in particular focused on the twelve lower, best-preserved, curved rows of seats, excluding the upper two rows in which most of the slabs were displaced from their initial position. Some of the slabs of the 12 lower rows were also excluded, owing to their poor preservation or dislocation. The coordinates of 183 points in total were included in our analysis. Based on the coordinates of each point and the approximated coordinates of the circle centre, estimated from the graphic technique, the equation of radius (distance) was defined as:

$$
\left(x_{i j}-x_{0}\right)^{2}+\left(y_{i j}-y_{0}\right)^{2}=R_{i}^{2} \text { (Equation 1) }
$$

where $x_{i j}, y_{i j}$ are the coordinates of the midpoint of the front edge of a certain block $i j, x_{0}$, $y_{\mathrm{o}}$ are the approximated coordinates of the circle centre and $R_{i}$ is the distance (radius) of 


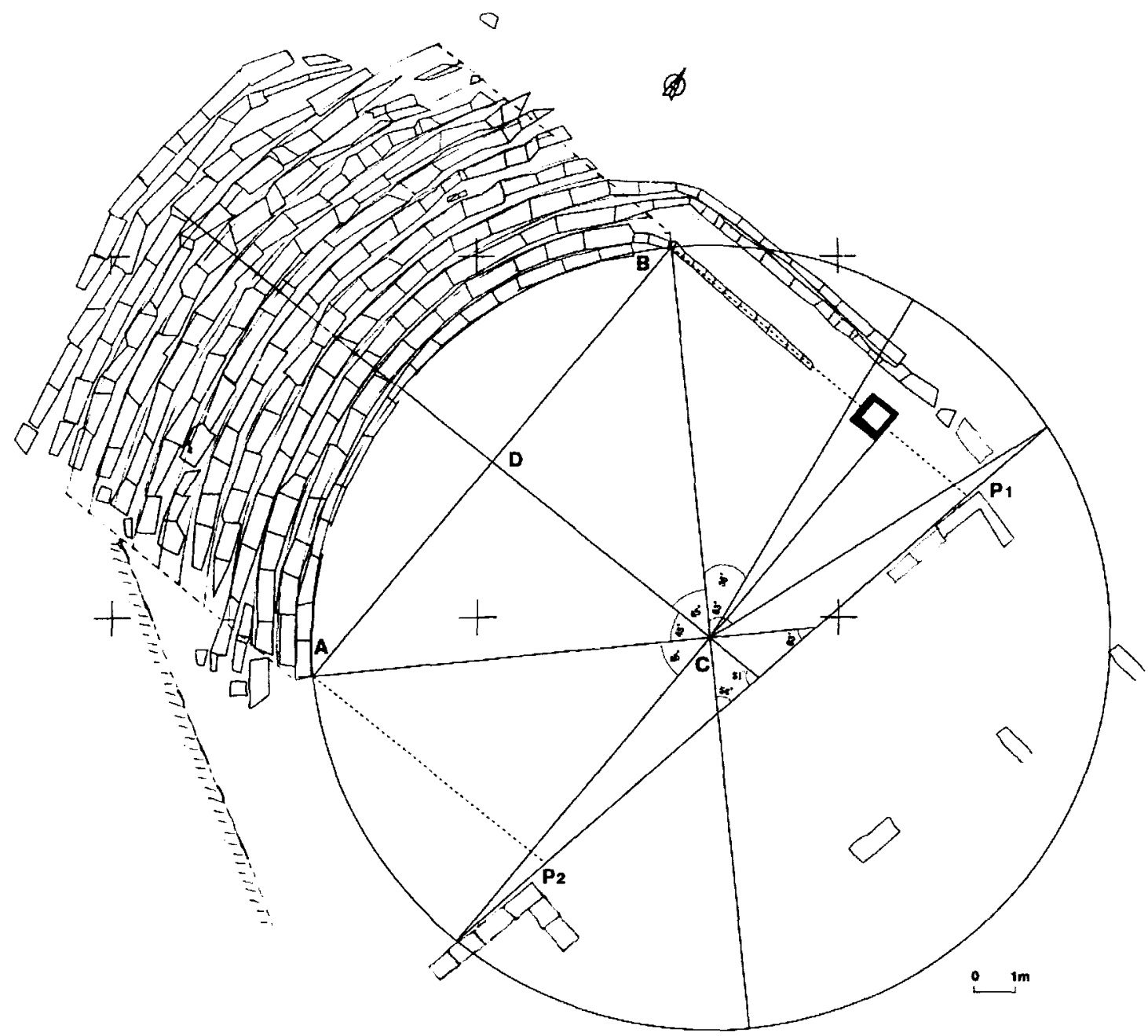

Fig. 9. Geometry of the Makyneia theatre using empirical techniques: best-fitting circles and straight lines fit to the rows of seats. Apparent geometric relationships are indicated.

this specific midpoint; $i$ corresponds to the row number and the $j$ corresponds to the slab number of the row. The distance of each slab from the circle centre was defined as a function of the radius of the lower curvilinear row and of the spacing of the theatre rows of seats. The spacing of the two lower rows seemed to be smaller than of that of the higher rows. Consequently the radius of each row (i) was estimated from the expression:

$$
\left.R_{i}=R_{1}+c+i \times d, i=0,1, \ldots, 12 \text { (Equation } 2\right)
$$

where $c$ is the width of the lowest row and $d$ the spacing between the upper rows (FIG. 7). 
Taylor series were used in order to transform equation (1) into the linear equation (3):

$$
\frac{x_{i j}-x_{0}}{R_{i}} \times \delta x+\frac{y_{i j}-y_{0}}{R_{i}} \times \delta y-R_{1}-c-n \times d=-R_{i} \text { (Equation 3) }
$$

using equation (2). TABLE 1 shows slabs used in the modelling and the approximated radius of each row. In this equation the unknown parameters are: the radius of the lower row $R_{1}$, the spacing between the lower two rows $c$, the spacing $d$ between the rest of the rows and the differences $\delta x, \delta y$ of the circles centres coordinates from their initial approximated values (FIG. 10).

TABLE 1. Number of blocks used in modelling and approximate radius of each row.

\begin{tabular}{rcc}
\hline Row $(i)$ & Blocks $(j)$ & Approximate radius $R_{i}(\mathrm{~m})$ \\
\hline 1 & 11 & 10.91 \\
2 & 14 & 11.46 \\
3 & 19 & 12.15 \\
4 & 19 & 12.84 \\
5 & 17 & 13.53 \\
6 & 18 & 14.22 \\
7 & 15 & 14.91 \\
8 & 14 & 15.60 \\
9 & 17 & 16.29 \\
10 & 13 & 16.98 \\
11 & 15 & 17.67 \\
12 & 11 & 18.36 \\
\hline
\end{tabular}

On the basis of equation (3) a linear system of $18_{3}$ equations with 5 unknown parameters was formed. The system was solved using standard Least Squares Method and the Mathematica 5.0 software. Results are shown in TABLE 2; for comparison, the results of the graphic approach are also shown; uncertainties of the latter are, however, at least an order of magnitude larger than those of the analytical technique.

Thus the parameters computed on the basis of the analytical technique are very similar to those of the graphic technique, although the corresponding uncertainties are very different, at least one order of magnitude larger for the graphic approach. The high accuracy of the results (standard error less than $3 \mathrm{~cm}$ ) is due to the high redundancy of the system $(183$ equations, 5 unknown parameters).

The three rows of slabs composing the linear wing were analytically approximated by straight lines, and their mean direction (shown by a dashed line in FIG. 10) was computed. Subsequently the direction of the chord $\mathrm{AB}$ and the angle formed between this chord and the mean line direction of the linear wing, $88.8^{\circ}$, were calculated. 
TABLE 2. Results of the adjustment (see FIG. 10 for explanation).

\begin{tabular}{cccc}
\hline Adjusted parameter & Adjusted value $(\mathrm{m})$ & Standard error $(\mathrm{cm})$ & Graphic estimate (m) \\
\hline \multicolumn{1}{c}{$\boldsymbol{\delta} \mathbf{x}$} & 0.0036 & 2.44 & \\
$\delta \mathbf{y}$ & 0.0044 & 2.22 & \\
Radius R of bottom row & 10.910 & 2.97 & 10.91 \\
Width c of bottom row & $0.54^{8}$ & 0.91 & 0.55 \\
Spacing d of other rows & 0.692 & 0.08 & 0.686 \\
\hline
\end{tabular}

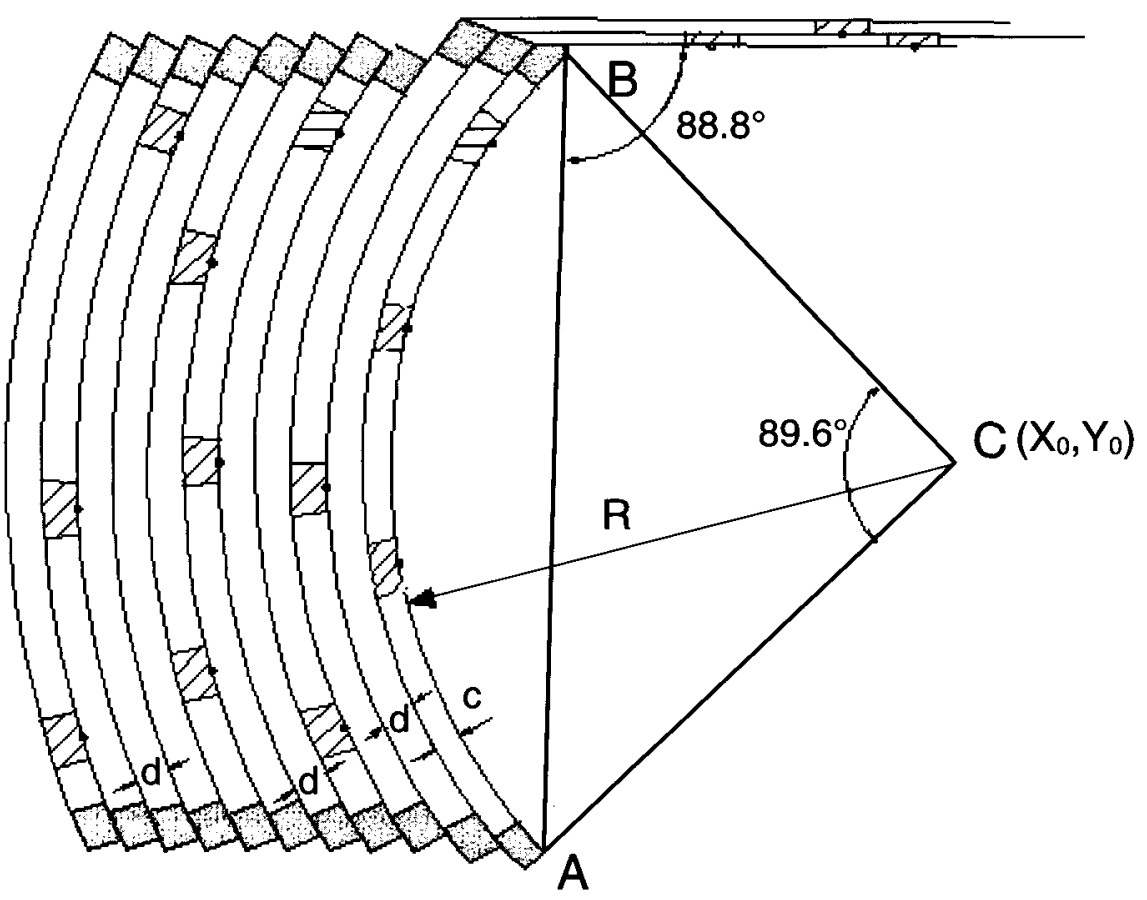

FIG. 10. Sketch of the theatre koilon indicating data input in its analytical study. 
A following step in our analysis was to calculate the angle corresponding to the chord of the lower row. The value of this angle, $89^{\circ} \pm 0.2^{\circ}$, was computed from the adjusted coordinates of the circle centre and the coordinates of the two terminal points of the lower row (A, B in FIG. 10). Within the errors of our data and analysis both these angles correspond to $90^{\circ}$. Interestingly, within the error limits of our calculations, the radii of the lowermost $(10.910 \mathrm{~m})$ and of the second row of seats $\left(11.45^{8} \mathrm{~m}\right)$ correspond to 33.33 and 35 Doric feet respectively (1 Doric foot $=0.327 \mathrm{~m}) .{ }^{18}$

\section{TyPOLOGY OF THE AnCIENT TheATRE}

The geometry of the ancient theatre derived from our modelling (FIG. 1 1) definitely differs from that of the typical ancient theatre of the Hellenistic or previous periods, ${ }^{19}$ especially as far as its $90^{\circ}$ design circle arc (instead of $14{ }^{\circ-200^{\circ}}$ for common theatres, ${ }^{20}$ the asymmetric proedria, and the possible oblique skene are concerned, and hence justifies its classification by Frederiksen as a unique theatre. ${ }^{21}$ Still, asymmetries, though of different types, have been noticed in other ancient theatres as well. For instance, the radii of curvature of circular wings are different in Thorikos, ${ }^{22}$ while the proedria thrones are at an eccentric location at Evonymon. ${ }^{23}$

A question arising is whether the surviving structure is representative of an original structure, or reflects a series of constructions at different times. The following arguments permit a preliminary answer to this question, at least as far as the cavea is concerned. First, the building material and the architectural style are identical in the whole of the structure, with the exception of the lower row of the linear wing, which is made of smaller blocks, probably because it was not used as a row of seats. Second, the geometric relationships presented above (a construction based on a design circle and a $90^{\circ}$ arc for the curvilinear wing and a linear wing normal to the corresponding chord) make it rather unlikely that the surviving structure is significantly different from the original one. And even if the linear wing, the seats of which overlap and partly cover the edge of the circular cavea (FIG. 8), represents a later addition, it respects the original plan to which it was fully adapted. Furthermore, a skene oblique to the design axis of the theatre was also adopted because of the asymmetric plan of the theatre and the need to improve visibility from the proedria seats.

\section{CONCLUSION}

The theatre of Makyneia is definitely of unusual shape, but it is based on a strict geometric plan which confirms Gebhard's conclusion that theatres, certainly in the Hellenistic and perhaps in previous periods, were constructed on the basis of a design plan. ${ }^{24}$ Yet, especially in smaller towns, architects had the liberty to deviate from typical models and adjust their plans according to environmental conditions, the need for increased seating capacity, the

${ }_{18}$ Dinsmoor n. 14, 54, n. 4, 257, n. 1.

19 O. A. W. Dilke, 'Details and chronology of Greek theatre caveas', $B S A 45(195 \mathrm{o}), 21-62$.

${ }^{20}$ Gebhard (n. 12), 377, Frederiksen (n. 16), 141.

"Frederiksen (n. 16), 141, 173.

${ }_{22}$ Palyvou (n. 16), fig. 8.

${ }_{23}$ O. Tzachou-Alexandri, 'The original plan of the
Greek theater reconsidered: the theater at Evonymon of Attica', in Roald F. Docter and Eric M. Moorman (eds), Proceedings of the $X V^{\text {th }}$ Congress of Classical Archaeology, Amsterdam, July I2-I 7, 1998 (Allard Pierson Series, 12; Amsterdam, 1999), text vol. $4^{20-3}$, plates vol. $3^{6}$.

${ }_{24}$ Gebhard (n. 18), 394. 


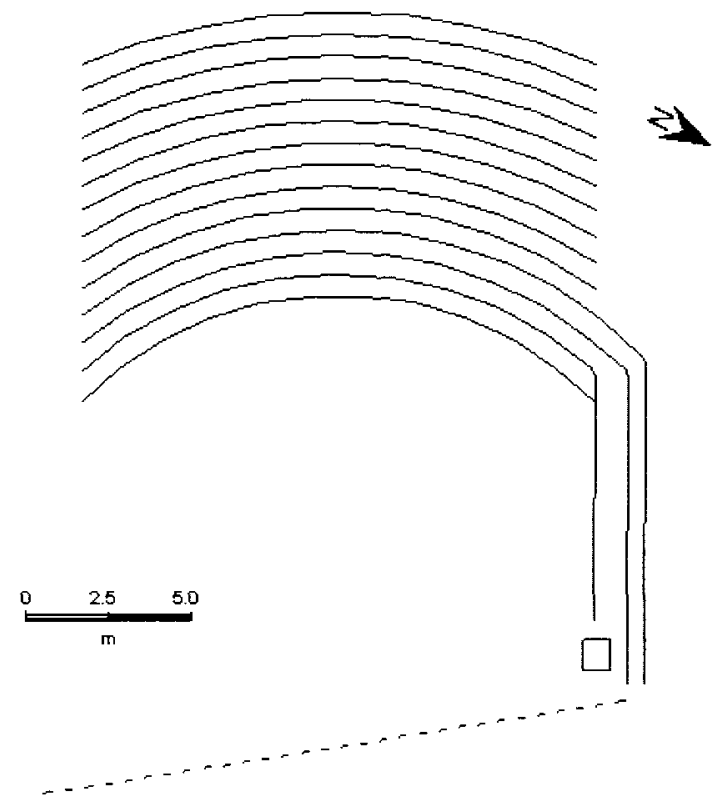

FIG. 11. Conceptual model of the koilon of the theatre of Makyneia.

availability of construction material and funding, as well as the special requirements of magistrates and donors. Our comparison of graphic and analytical techniques also revealed that the pattern of certain ancient structures can be satisfactorily defined using simple graphic techniques, but for accurate results analytical techniques are necessary.

Geodesy Laboratory,

Dept. of Civil Engineering,

University of Patras
Stathis C. Stiros

Panos A. Psimoulis

Christos L. Kolonas 